\title{
Impacts of social distancing on cancer care during the COVID-19 pandemic: Hong Kong experience - RETRACTION
}

\section{Retraction}

Cite this article: Chan W-L, Ho P, Yuen K-K (2021). Impacts of social distancing on cancer care during the COVID-19 pandemic: Hong Kong experience - RETRACTION. Palliative and Supportive Care 19, 641-641. https://doi.org/ $10.1017 /$ S1478951521001309

\section{Wing-Lok Chan, Patty Ho and Kwok-Keung Yuen}

https://doi.org/10.1017/S1478951520000541, published by Cambridge University Press, 29 June 2020

Cambridge University Press would like to issue a retraction for the preliminary accepted manuscript publication of this article (Chan et al. 2020a). The article was simultaneously submitted and later published in BMJ Supportive \& Palliative Care (Chan et al. 2020b), and Cambridge University Press did not have appropriate permission to publish the Accepted Manuscript version of this article.

The publisher apologizes to the author and to the editors of BMJ Supportive \& Palliative Care for this error.

\section{References}

Chan W-L, Ho P, Yuen K-K (2020a) Impacts of social distancing on cancer care during the COVID-19 pandemic: Hong Kong experience. Palliative \& Supportive Care. https://doi.org/10.1017/S1478951520000541

Chan W-L, Ho P-YP, Yuen K-K (2020b) Social distancing and cancer care during the COVID-19 pandemic. BMJ Supportive \& Palliative Care. http://dx.doi.org/10.1136/bmjspcare-2020-002489

\section{CAMBRIDGE UNIVERSITY PRESS}

